\title{
Housing conditions and mental health in a disadvantaged area in Scotland
}

\author{
Jane L Hopton, Sonja M Hunt
}

\begin{abstract}
Objective - To examine the mental health impact of different aspects of poor housing. Design - This was a post hoc analysis of data from a household interview survey. Setting - A public sector housing estate on the outskirts of Glasgow.

Subjects - These comprised 114 men and 333 women aged between 17 and 65 from 451 households.

Measures - Dependent variable: scoring $\geqslant 5$ on the 30 item general health questionnaire (GHQ30). Independent variables: self reported data on household composition, whether ill health was a factor in the move to the current dwelling, length of time at address, household income, whether the respondent was unemployed, chronic illness, and 6 problems with the dwelling.

Results - Reporting a problem with dampness was significantly and indpendently associated with scores of $\geqslant 5$ on the GHQ30 after controlling for possible confounding variables.

Conclusion - Initiatives to tackle housing dampness may be important in developing a strategy to improve mental health for the study area. More research on the mental health impact of different aspects of poor housing is required.
\end{abstract}

( $($ Epidemiol Community Health 1996;50:56-61)

The large demand placed upon health services as a result of mental ill health led to the inclusion of mental health as part of the strategy for The Health of the Nation. ${ }^{1}$ It has been estimated that mental ill health accounts for $20 \%$ of the total NHS expenditure. ${ }^{2}$ General practice surveys and morbidity statistics indicate that up to one third of all patients who consult their general practitioners are seeking help for emotional distress. ${ }^{3}$ These estimates, which are based on routinely available morbidity data, will underestimate the health burden which mental distress places on the community. ${ }^{4}$

A variety of social and material factors have now been shown to influence mental health and The Health of the Nation acknowledges that "family life, education, housing and employment al influence psychological health". However, with regard to the relationship between housing and health, the introductory section to this strategy states that although "good housing is important to good health, the interdependence between factors such as occupational class, income, unemployment, housing and lifestyle makes it difficult to assess which health effects are specifically attributable to it. ${ }^{11}$

The issue of confounding variables which cluster together is one of the major methodological problems facing researchers in the field of social inequalities in health. ${ }^{56}$ It has been a particular difficulty in relation to housing and mental health. ${ }^{78}$

\section{RESEARCH ON THE RELATIONSHIP BETWEEN}

MENTAL HEALTH AND HOUSING

Although the impact of housing on physical health is now acknowledged, ${ }^{9-11}$ there has been relatively little research on the relationship between housing conditions and mental health. Two themes underpin the research that has been carried out: the influence of housing on social relationships and the mental health impact of poor housing. ${ }^{1213}$

THE INFLUENCE OF HOUSING ON SOCIAL RELATIONSHIPS

The first and most common theme is underpinned by the hypothesis that the housing environment has an impact on social relationships and thereby affects mental health. ${ }^{14-29}$ Two important issues in this tradition are those of rehousing ${ }^{714222628}$ and crowding in the dwelling. ${ }^{713161820242530-32}$

Studies of the impact of rehousing to higher quality housing showed conflicting findings. All, however, showed the importance of taking account of changes in distance from, and hence contact with, relatives and old friends as well as changes in housing conditions associated with the move.

Crowding has deleterious effects on mental health by enforcing social contact. ${ }^{6202431}$ Being in the continual presence of others has been shown to impose a mental strain on both children and adults. ${ }^{29}$ The availability of routine data on the number of rooms within a dwelling and the number of inhabitants has given rise to attempts to develop "objective" measures of crowding. ${ }^{31}$ Other research has suggested that perceptions of crowding are also important in determining the level of emotional distress. ${ }^{32}$

Other issues falling within this theme of research are those of external population density and architectural design. ${ }^{7161723303334} \mathrm{~A}$ review of research on this theme concluded that a major weakness was that very few of the studies considered the impact of other demographic, social, and economic factors. ${ }^{7}$

\section{THE MENTAL HEALTH IMPACT OF POOR} HOUSING

A second, less popular, theme of research on the relationship between housing and mental 
health has looked at the impact of poor housing. Within this theme, three approaches to the definition and measurement of "poor" housing are discernible. One approach has been termed "ecological" and this has involved comparing the health of residents in different areas. ${ }^{7356}$ Again, a major weakness of this type of study is the difficulty of controlling directly for other social and economic factors.

A second approach has been to consider individuals' satisfaction with their housing. This approach has been criticised on the grounds that dissatisfaction with housing may be a consequence of emotional distress rather than the cause of it. ${ }^{37}$

Thirdly, some studies have examined the impact of specific features of housing. ${ }^{83839}$ Noise, particularly unpredictable, intermittent and uncontrollable noise can have deleterious psychological effects. ${ }^{314041}$ Brown and Harris found that housing dampness was one of the factors associated with mental ill health in their study of the origins of depression in women. ${ }^{30}$ Four studies looking specifically at the health impact of damp housing showed a deleterious effect on mental health. Hyndman ${ }^{42}$ reported a strong association between both objective and subjective measures of dampness and reported depression and Martin et al. ${ }^{9}$ reported an association between emotional distress and independently assessed dampness. Neither of these two studies directly controlled for other social and economic factors. Platt et al ${ }^{\beta}$ showed a significant relationship between damp housing and women's scores on the general health questionnnaire (GHQ). This was independent of social class, employment status, and household income. Most recently, damp housing has been shown to be associated with a significantly greater likelihood of reporting problems with lack of energy, sleep, and social isolation after adjusting for age, sex, and social class. ${ }^{43}$

In summary, the studies of housing and mental health outlined above have varied in the extent to which they have considered possible confounding with other social and economic factors known to be associated with housing. There has been relatively little research on the mental health impact of specific aspects of poor housing. None of the studies in this area have examined the relative impact of different features of poor housing.

A second methodological problem besets research on social inequalities and health and also needs to be addressed: the issue of how to measure socioeconomic status. ${ }^{44}$

Many of the studies described above which have attempted to control for the influence of economic status have used occupational based measures of socioeconomic position. These are proxy rather than direct measures of material wealth and are known to be problematic. ${ }^{45}$ They are based upon a classification of formal occupations and therefore do not cover people who are unemployed, who are no longer economically active or women who are not in formal employment. ${ }^{46}$ More direct measures of material circumstances, such as household income, may better expose and explain the extent and nature of social inequalities in health. ${ }^{44547}$ Data on income level is not routinely available. As a consequence, very little research has looked explicitly at the health impact of income level.

Unemployment is also known to be associated with mental ill health. ${ }^{43849}$ This may be partly a consequence of loss of income, but research has also pointed to other aspects of the experience of unemployment which are associated with poorer mental health such as role loss, boredom, and uncertainty. ${ }^{50}$ Analyses of socioeconomic circumstances need to consider unemployment as well as income level.

This paper uses self reported data from an interview survey of living conditions to examine the mental health impact of specific housing problems while controlling for other social and economic factors.

\section{Method}

BACKGROUND

The data presented below were collected as part of a study which aimed to assess the impact of improved housing conditions, specifically damp and cold, upon health and wellbeing.

The survey was carried out on a local authority housing estate in Glasgow. The estate was notorious for problems of dampness and a technical survey conducted in 1983 found that $57.9 \%$ of the dwellings were damp. ${ }^{51} \mathrm{Be}-$ cause of the problems of cold and dampness the estate had been designated "hard to heat" and people receiving state benefits were entitled to an additional heating allowance.

The estate contained 1338 households. It is situated on the outskirts of Glasgow and is clearly identifiable and geographically contained. The blocks of flats were system built, up to five storeys high with deck access. From being an attractive and modern semirural alternative to older inner city housing, it was generally felt that the area had "gone downhill" and the local authority found flats that were available difficult to let.

\section{PROCEDURE}

Of the 1338 households in the estate, some blocks had been used in a pilot scheme of housing improvements and were excluded from this study. Thus, the number of households eligible for inclusion was 997 . A team of trained interviewers attempted to contact residents in all eligible households to ask them to take part. Respondents who agreed to take part were interviewed in their own homes.

Interviewers were instructed to try to obtain interviews with the person mainly responsible for the household and, where relevant, the children. This explains the high proportion of women in the sample.

\section{CONTENT OF THE INTERVIEW}

The structured interview schedule was adapted from a previously validated instrument. ${ }^{10}$ After the interview respondents aged under 65 were asked to complete a standardised measure of emotional distress, the 30 item GHQ 
(GHQ30). ${ }^{3252}$ Respondents over the age of 65 completed a multidimensional measure of distress and are not included in this analysis.

\section{VARIABLES USED IN THE ANALYSIS}

Demographic information

Respondents were asked their age and civil status (married/living together/single/divorced/ separated/widowed), the total number of people living in the household, the number of children under 16 living in the household, the length of time at the current address, and whether they had moved to their current address because of ill health.

\section{Measure of mental distress: the GHQ30}

The GHQ was originally devised as a screening instrument for mental disorder but has been used in many community surveys and in general practice settings. ${ }^{3252}$ The standard 0/0/1/1 system was used to score the GHQ30. Most studies have used a threshold score of five or more indicating "caseness", that is the probability of being a psychiatric case is greater than $50 \%$ (GHQ manual). Although the concept of a "case" is somewhat incompatible with the context of this study the skewed distribution of the scores necessitated categorisation for statistical analysis.

Chronic illness

Respondents were asked if they had any chronic illnesses (yes/no).

\section{Household income}

Respondents were asked to estimate the net weekly household income after deductions for tax and national insurance. They were given a choice of $£ 20$ bands up to greater than $£ 300$ per week. Five categories of household composition were identified and those people living in households where the net weekly household income was less than the median value for that category were defined as low income households. The categories and low net weekly household income were as follows: single person (less than $£ 60$ per week), single person with one or more children (less than $£ 80$ per week), two adults (less than $£ 100$ per week), two adults with children (less than $£ 120$ per week), three or more adults with or without children (less than $£ 140$ per week).

\section{Unemployment}

Respondents were asked what they did and responses were categorised as unemployed at present or not.

\section{Housing conditions}

Respondents were given a check list of 6 problems associated with dampness and asked to say for each whether they had the problem. The check list was identical to that used in a previous study. ${ }^{10}$ In the analysis below re- sponses are dichotomised as reporting any versus none of the problems and included in the analysis as one variable in the list of different housing problems.

The interview schedule also included a second check list of housing problems including cold, noise and, crowding. Other problems were derived from answers to an open ended question about problems with housing from an unpublished face to face interview survey carried out by the researchers in a deprived community in Edinburgh in the year before the current study. These were: problems because the dwelling was an easy target for burglars, problems because the dwelling was an easy target for vandals, and problems because the dwelling was in a generally poor state of repair.

\section{DATA ANALYSIS}

The analysis was carried out in two stages The first stage identifies sociodemographic and economic variables which are significantly associated with scores on the dependent variable. The second stage of the analysis examines the impact of different aspects of poor housing. Variables identified in stage 1 as having significant independent associations with the dependent variable are included as possible confounding variables.

Data were analysed using the SPSSX statistical package. Univariate analyses using categorical variables used the $\chi^{2}$ statistic. Multivariate analyses used stepwise logistic regression. Odds ratios with $95 \%$ confidence intervals $(95 \% \mathrm{CI})$ are reported for significant independent variables.

\section{Results}

RESPONSE RATES

Interviews were carried out in 532 of the 997 eligible households. Altogether 135 households were unoccupied. No contact was made with 221 of the households despite repeated call backs at different times of the day. There were only 109 refusals. The response rate was $63 \%$ once the number of unoccupied households was removed from the denominator. The refusal rate was $13 \%$. Some 451 of these interviews were with respondents under the age of 65 who completed the GHQ and these form the basis of the following analysis.

\section{CHARACTERISTICS OF THE SAMPLE}

The sample consisted of 114 men $(25.5 \%)$ and 333 women $(74.5 \%)$. The mean age of the sample was $34 \cdot 1$ years $(n=424)$. Scores on the GHQ30 ranged from 0 to 30 . The modal response was 0 , mean $6 \cdot 75$, and SD $7 \cdot 41$. A total of $45.9 \%$ (207) respondents scored five or more. Other social, economic, and housing characteristics are shown in table 1.

\section{STAGE 1: SOCIODEMOGRAPHIC AND} ECONOMIC FACTORS, CHRONIC ILLNESS, AND EMOTIONAL DISTRESS

Table 2 shows that respondents who lived with children under 16 in the household and re- 
Table 1 Characteristics of the sample

\begin{tabular}{lrr}
\hline Characteristics & $\%$ & \multicolumn{1}{c}{$N o$} \\
\hline Sociodemographic characteristics & & \\
Age: & & \\
17 to $25 \mathrm{y}$ & $29 \cdot 0$ & 123 \\
26 to 40 y & $45 \cdot 0$ & 191 \\
41 to 64 y & $25 \cdot 0$ & 110 \\
Lived in area less than 1 y & $33 \cdot 0$ & 153 \\
Moved to current dwelling because of ill & & \\
health & $7 \cdot 1$ & 32 \\
Living with children under 16 y & $56 \cdot 3$ & 254 \\
Single adult with children under 16 y & $16 \cdot 9$ & 76 \\
Living alone & $25 \cdot 5$ & 115 \\
Married or living with partner & $51 \cdot 0$ & 230 \\
Single & $23 \cdot 6$ & 106 \\
Divorced/windowed/separated & $25 \cdot 3$ & 114 \\
& & \\
Chronic illness & & \\
Has a chronic illness & $42 \cdot 8$ & 193 \\
& & \\
Economic characteristics & & \\
Unemployed & $34 \cdot 6$ & 156 \\
Living in a low income household & $42 \cdot 0$ & 185 \\
& & \\
Housing conditions & & \\
Dampness & $56 \cdot 8$ & 256 \\
Cold & $55 \cdot 7$ & 251 \\
Easy target for burglars & $54 \cdot 3$ & 245 \\
Easy target for vandals & $53 \cdot 4$ & 241 \\
Badly designed & $39 \cdot 7$ & 179 \\
Poise & $39 \cdot 2$ & 177 \\
Over repair & $38 \cdot 4$ & 173 \\
\hline & $14 \cdot 2$ & 64 \\
\hline
\end{tabular}

ported having a chronic illness, living in a low income household, or being unemployed were significantly more likely to score 5 or more on the GHQ30. There were no significant differences in the percentage scoring 5 or more on the GHQ30 according to age, sex, being the single adult in a household with children, civil status, having lived in the area for less than a year, or having moved to the current dwelling because of ill health.

A stepwise logistic regression analysis was carried out to determine which of the above

Table 2 Percentage of respondents scoring $\geqslant 5$ on the general health questionnaire 30 according to sociodemographic and economic factors and chronic illness

\begin{tabular}{|c|c|c|c|c|}
\hline & & $\begin{array}{l}\text { \% scoring } \\
\geqslant 5 \text { on } \\
\text { GHQ30 }\end{array}$ & $N o^{*}$ & $\chi^{2} p$ \\
\hline Sex & $\begin{array}{l}\text { Male } \\
\text { Female }\end{array}$ & $\begin{array}{l}42 \cdot 1 \\
47 \cdot 4\end{array}$ & $\begin{array}{l}114 \\
333\end{array}$ & \\
\hline Age group & $\begin{array}{l}17 \text { to } 25 \mathrm{y} \\
26 \text { to } 40 \mathrm{y} \\
41 \text { to } 64 \mathrm{y}\end{array}$ & $\begin{array}{l}52 \cdot 8 \\
47 \cdot 6 \\
40 \cdot 9\end{array}$ & $\begin{array}{l}123 \\
191 \\
110\end{array}$ & \\
\hline Lived in area less than one year & $\begin{array}{l}\text { No } \\
\text { Yes }\end{array}$ & $\begin{array}{l}43 \cdot 3 \\
51 \cdot 0\end{array}$ & $\begin{array}{l}298 \\
153\end{array}$ & \\
\hline $\begin{array}{l}\text { Moved to current dwelling } \\
\text { because of ill health }\end{array}$ & $\begin{array}{l}\text { No } \\
\text { Yes }\end{array}$ & $\begin{array}{l}44 \cdot 9 \\
59 \cdot 4\end{array}$ & $\begin{array}{r}419 \\
32\end{array}$ & \\
\hline Living with children under $16 \mathrm{y}$ & $\begin{array}{l}\text { No } \\
\text { Yes }\end{array}$ & $\begin{array}{l}39 \cdot 6 \\
50 \cdot 8\end{array}$ & $\begin{array}{l}197 \\
254\end{array}$ & $<0.05$ \\
\hline $\begin{array}{l}\text { Single adult with children } \\
\text { under } 16 \mathrm{y}\end{array}$ & $\begin{array}{l}\text { No } \\
\text { Yes }\end{array}$ & $\begin{array}{l}45 \cdot 9 \\
46 \cdot 1\end{array}$ & $\begin{array}{r}375 \\
76\end{array}$ & \\
\hline Living alone & $\begin{array}{l}\text { No } \\
\text { Yes }\end{array}$ & $\begin{array}{l}47 \cdot 3 \\
41 \cdot 7\end{array}$ & $\begin{array}{l}336 \\
115\end{array}$ & \\
\hline Civil status & $\begin{array}{l}\text { Married or living } \\
\text { with partner } \\
\text { Single } \\
\text { Divorced/widowed/ } \\
\text { separated }\end{array}$ & $\begin{array}{l}48 \cdot 7 \\
36 \cdot 8 \\
49 \cdot 1\end{array}$ & $\begin{array}{l}230 \\
106 \\
114\end{array}$ & \\
\hline Respondent unemployed & $\begin{array}{l}\text { No } \\
\text { Yes }\end{array}$ & $\begin{array}{l}42 \cdot 4 \\
52 \cdot 6\end{array}$ & $\begin{array}{l}295 \\
150\end{array}$ & $<0.05$ \\
\hline $\begin{array}{l}\text { Living in a low income } \\
\text { household }\end{array}$ & $\begin{array}{l}\text { No } \\
\text { Yes }\end{array}$ & $\begin{array}{l}40 \cdot 8 \\
53 \cdot 5\end{array}$ & $\begin{array}{l}225 \\
185\end{array}$ & $<0.01$ \\
\hline Has a chronic illness & $\begin{array}{l}\text { No } \\
\text { Yes }\end{array}$ & $\begin{array}{l}40 \cdot 3 \\
53 \cdot 4\end{array}$ & $\begin{array}{l}258 \\
193\end{array}$ & $<0.01$ \\
\hline
\end{tabular}

* Total $\mathrm{N}$ values may be less than 451 because of missing data factors made an independent contribution to scoring 5 or more on the GHQ30. Reporting having a chronic illness, living with children under 16 , living in a low income household, and being unemployed were the only significant independent predictors (chronic illness: odds ratio $(95 \% \mathrm{CI}) 1.76)(1 \cdot 16,2 \cdot 68) \mathrm{df}=1 \mathrm{p}=$ 0.0066 ; living with children under 16: odds ratio $1.75(1.14,2.69) \mathrm{df}=1 \mathrm{p}=0.0087$; respondent unemployed: odds ratio 1.59 (1.01, $2.5) \mathrm{df}=1 \mathrm{p}=0.043$; living in a low income household: odds ratio $1.59(1.01,2.44) \mathrm{df}=1$ $p=0.03 n=413)$. Other variables entered into the equation but not included in the final model were: age, sex, having lived in the area for less than one year, having moved to the current dwelling because of ill health, civil status, being the single adult in a household with children, and living alone.

\section{STAGE 2: HOUSING CONDITIONS AND}

\section{EMOTIONAL DISTRESS}

Intercorrelation among the housing variables was examined. Two of the housing variables were excluded from the analysis because they correlated highly with other variables (correlation coefficient greater than $0 \cdot 3$ ). Reporting that the house was an easy target for vandals correlated highly with reporting that the house was an easy target for burglars (Spearman correlation coefficient 0.69 ). Reporting that the house was badly designed correlated with reporting that the house was too cold $(0 \cdot 31)$, that the house was an easy target for burglars $(0 \cdot 37)$ and that the house was in a poor state of repair $(0 \cdot 36)$. Reporting that the house was badly designed and reporting that the dwelling was an easy target for vandals were therefore excluded from the analysis.

Table 3 shows that reporting a problem with dampness, that the dwelling was too cold, and the dwelling an easy target for burglars were all significantly associated with scoring 5 or more on the GHQ30.

Stepwise logistic regression analysis was carried out to examine the independent contribution of the different housing conditions to scoring 5 or more on the GHQ30. Having a chronic illness, living in a low income household, living with children under 16, and being unemployed were entered into the model along with all six housing variables. The final equation is summarised in table 4 .

Being unemployed, having a chronic illness, being in a low income household, living with children under 16 and reporting a problem with dampness were all significant independent predictors of scoring 5 or more on the GHQ30.

This regression analysis was repeated excluding respondents who reported that they had moved to their current dwelling because of ill health. This analysis $(n=408)$ also showed significant independent effects of having a chronic illness (odds ratio (95\% CI) $2 \cdot 05(1 \cdot 33$, $3.14) \mathrm{df}=1 \mathrm{p}=0.0008)$; living in a low income household (odds ratio $=2 \cdot 0(1 \cdot 31,3.05) \mathrm{df}=$ $1 \mathrm{p}=0.001$ ); problem with dampness (odds ratio $=1.88(1 \cdot 23,2 \cdot 89) \mathrm{df}=1 \mathrm{p}=0.0031)$; and living with children under 16 (odds ratio $=1.53$ 
Table 3 Percentage of respondents scoring $\geqslant 5$ on the general health questionnaire 30 and reporting of specific housing problems

\begin{tabular}{lllll}
\hline & & $\begin{array}{l}\% \text { scoring } \geqslant \text { on } \\
\text { on GHQ30 }\end{array}$ & No & $\chi^{2} p$ \\
\hline Problem with dampness & No & $36 \cdot 9$ & 195 & \\
& Yes & $52 \cdot 7$ & 256 & 0.001 \\
Too cold & No & $39 \cdot 5$ & 200 & \\
& Yes & $51 \cdot 0$ & 251 & 0.05 \\
Noise & No & $43 \cdot 4$ & 274 & \\
& Yes & $49 \cdot 7$ & 177 & NS \\
Easy target for burglars & No & $40 \cdot 8$ & 206 & \\
& Yes & $50 \cdot 2$ & 245 & 0.05 \\
Poor state of repair & No & $42 \cdot 8$ & 278 & \\
& Yes & $50 \cdot 9$ & 173 & NS \\
Overcrowded & No & $46 \cdot 0$ & 387 & \\
& Yes & $45 \cdot 3$ & 64 & NS \\
\hline
\end{tabular}

Table 4 Summary of logistic regression analysis: significant predictors of scoring $\geq 5$ on the general health questionnaire 30

\begin{tabular}{lllll}
\hline Independent variable & Odds ratio & $(95 \%$ CI $)$ & $d f$ & $p$ \\
\hline Chronic illness & 1.99 & $(1.32,3.02)$ & 1 & 0.0008 \\
Problem with dampness & 1.76 & $(1.17,2 \cdot 66)$ & 1 & 0.0056 \\
Living with children under 16 y & 1.75 & $(1.15,2 \cdot 68)$ & 1 & 0.0083 \\
Living in a low income household & 1.61 & $(1.06,2 \cdot 44)$ & 1 & 0.0231 \\
Respondent unemployed & 1.55 & $(0.99,2 \cdot 42)$ & 1 & 0.0483 \\
\hline
\end{tabular}

Variables entered but not in the final equation: too noisy, too cold, poor state of repair, overcrowded, easy target for burglars. $\mathrm{N}=414$.

$(0.99,2.3 \overline{5} \mathrm{df}=1 \mathrm{p}=0.0473$. Variables entered but not in the final equation were: respondent unemployed, too noisy, too cold, poor state of repair, overcrowded, and easy target for burglars.

\section{Discussion}

The purpose of the analysis presented here was to examine whether different aspects of poor housing have an impact on the mental health of adults independently of other social and economic factors.

The economic and housing conditions of the sample as a whole were poor and levels of emotional distress were very high. Emotional distress is known to be an important dimension of the experience of chronic illness ${ }^{53}$ and it is therefore not surprising that having a chronic illness was most strongly associated with emotional distress in this study. One aspect of poor housing, namely reporting a problem with dampness, was significantly and independently associated with poorer mental health.

Certain methodological issues have to be addressed. The achieved sample size was lower than expected because of the large number of unoccupied dwellings. It was not possible to determine differential response rates for age sex strata as no details of the occupants of households who refused to take part or who could not be contacted were available. There were relatively few refusals. The overall response rate was good, giving reasonable confidence that the sample was representative of the area.

The analysis is based on subjective measures of housing conditions. The use of subjective data has been, and remains, a particular difficulty in research on housing and health. It is difficult to reconcile the use of subjective data which is open to reporting bias with a concern for scientific objectivity in epidemiology. It is also important to acknowledge that there are some aspects of housing for which objective measures may be equally inappropriate. ${ }^{54}$ Physiological and psychological responses are known to vary among individuals and therefore objective measures of conditions may bear little relationship to the degree of distress and discomfort experienced.

In terms of the analysis presented here it is important to consider the argument that the findings could be explained by respondents with poorer mental health being more likely to perceive and report their housing conditions as poor. A number of factors make this explanation less likely. Firstly, in relation to reporting problems with dampness, an independent technical survey of the area found a similar proportion of households to be affected as reported by respondents. ${ }^{51}$ A previous study which used both objective and subjective measures of dampness found that respondents were more likely to under report the presence of dampness. ${ }^{10}$

Secondly, if respondents with poor mental health perceived and reported their housing conditions as poor then we would expect each feature of housing to be equally associated with poorer mental health. This was not the case, only some of the housing problems were significantly associated with emotional distress.

There are a number of possible explanations for the association of dampness with emotional distress. Recent research comparing home and formal work environments has drawn attention to the additional stress that poor housing conditions impose on the tasks of daily living. ${ }^{55}$ Damp and mould can cause considerable damage to property and thus add financial burdens to those already struggling on low incomes. Maintaining a clean house in the face of recurring visible mould is difficult and is likely to be a particular difficulty for women. The process of trying to get rehoused may be a further souce of frustration which could easily compound feelings of powerlessness. There may be a reluctance to invite friends and family into a damp and mouldy home. Furthermore, dampness may give rise to concerns about the effects on the health of household members, particularly if these include children or people with poor respiratory health.

A further issue which requires to be addressed is that of selection bias or "downward drift", that is that the findings are a result of people with poor health drifting into poor economic and housing circumstances. ${ }^{56}$ This issue needs to be considered at two levels, firstly in terms of selection into the study area and secondly with regard to selection within the study sample.

Given that the study area was notorious for dampness and for being "difficult to let" it is likely that housing allocation policies, whether formal or informal, lead to selection. The sample is clearly not representative of the general population and therefore the analysis focuses on differences within the sample. The impact of specific housing conditions and low income on mental health was independent of chronic illness and this makes it unlikely that 
the within sample differences could be explained by people with the poorest health being more likely to be in low income or damp households. The finding that the effects of low income and dampness were significant, even when respondents who had moved to their current dwelling as a result of ill health were removed from the analysis, further reduces the likelihood of the findings being explained by selection. Moreover, it could be argued that finding significant independent effects of housing conditions and income within a relatively homogenous sample ilustrates the "fine grain" of the health consequences of social stratification. ${ }^{45}$

\section{CONCLUSION}

Our results showed that dampness can be associated with poorer mental health after controlling for other possible confounding factors. The issue of confounding variables can easily diffuse pressure for policy initiatives to tackle deprivation. ${ }^{5}$ Initiatives aimed at remedying a single factor may be expected to have little effect because of the remaining contributory factors. Conversely, it is difficult to tackle multiple factors simultaneously. Our findings suggests that it is important to address the problem of housing dampness as part of a strategy for mental health for the study area.

The mental health impact of poor housing conditions has been relatively neglected. Further research is needed to assess the mental health burden of poor housing and to reassess the importance of housing in a national strategy for mental health.

1 Department of Health. The Health of the Nation: a strategy for health in England. London: DHSS, 1992.

2 Department of Health. The Health of the Nation: a consultative document for England and Wales. London: DHSS, 1991.

3 Corney RH. A survey of professional help sought by patients for psychosocial problems. Br f Gen Pract 1995;40:365-8.

4 Goldberg D, Huxley DF. Mental illness in the community: the pathway to psychiatric care. London: Tavistock, 1980.

5 Carr-Hill R. The inequalities in health debate: a critical review of the issues. Fournal of Social Policy 1992;16: 509-42.

6 Macintyre $S$. The patterning of health by social position in contemporary Britain: directions of sociological research. Soc Sci Med 1986;23:393-415.

7 Kasl SV. Effects of housing on mental and physical health Man-Environment Systems 1974;4:207-26.

8 Platt SD, Martin CJ, Hunt SM. The mental health of women with children living in deprived areas of Great Britain: the role of living conditions, poverty and unemployment. In: Goldberg D, Tantam D, eds. The public health impact of mental disorder. Gottinggen: Hagrefe and Huber, 1990.

9 Martin CJ, Platt SD, Hunt SM. Housing conditions and ill-health. BMF 1987;294:1125-7.

10 Platt SD, Martin CJ, Hunt SM. Damp housing, mould growth, and symptomatic health state. $B M F$ 1989;298: 1673-8.

11 Dales RE, Zwanenburg H, Burnett R, Franklin CA. Respiratory health effects of home dampness molds among Canadian school children. Am $\mathcal{f}$ Epidemiol 1991;134:196203.

12 Hopton JL. It drives you up the wall: mental health and housing. Health and Hygiene 1993;4:150-4.

13 Stewart W. Children in flats: a family study. London: NSPCC, 1970.

14 Martin FM, Brotherston JHF, Chave SPW. Incidence of neurosis on a new housing estate. Br F Prev Soc Med 1957; 11:196-202.

15 Wilner D, Walkley RP, Schram JM, Pinkerton TC, Tayback $M$. Housing as an environment factor in mental health. Am $\mathcal{f}$ Public Health 1960;50:55-63.

16 Moore NC. Social aspects of flat dwelling. Public Health 1975;89:418-31

17 Gillis AR. High rise housing and psychological strain. $f$ Health Soc Behav 1977;18:418-31.
18 Booth A, Cowell J. Crowding and health. F Health Soc Behav 1976;17:204-20.

19 Duvall D, Booth $\mathrm{A}$. The housing environment and women's health. $\mathcal{F}$ Health Soc Behav 1978;19:410-17.

20 Gabe J, Williams P. Is space bad for your health? The relationship between crowding in the home and emotional distress in women. Sociology of Health and Illness 1986;8: 351-71.

21 Gabe J, Williams P. Women: housing and mental health. Int f Health Serv 1987;17:667-79.

22 Elton PJ, Packer JM. A prospective randomised trial of the value of rehousing on the grounds of ill-health. $f$ Chron Dis 1986;39:221-7.

23 Hopton JL, Hunt SM. Changing housing conditions in relation to health and well-being. Edinburgh: University of Edinburgh, 1989.

24 Popay J, Bartley M. Conditions of labour and women's health. In: Martin CJ, McQueen DV, eds. Readings for a new public health. Edinburgh: Edinburgh University Press, new public 1989 .

25 Littlewood J, Tinker A. Families in flats. London: HMSO, 1981

26 Hare E, Shaw G. Mental health on a new housing estate London: Oxford: Oxford University Press, 1965.

27 Ineichen B, Hooper D. Wives mental health and children's behaviour problems in constrasting residential areas. Soc Sci Med 1974;8:369-74.

28 Wilner D, Walkley R, Pinkerton T, Tayback M. The housing environment and family life. Baltimore: The Johns Hopkin Press, 1969.

29 Hartup W. Children and their friends. In: Carson D ed. Man-environment interactions: evaluation and applications. Milwaukee: Environmental Design Research Association, 1978 .

30 Kasl SV, Harburgh E. Mental health and the urban environment: some doubts and second thoughts. $\mathcal{F}$ Health

31 Acheson D. Health and housing - annual lecture. I Roy Soc Health December 1991;236-43.

32 Goldberg DP. The detection of psychiatric illness by questionnaire. Oxford: Oxford University Press, 1972.

33 Moore NC. Psychiatric illness and living in flats. $\mathrm{Br}$ Psychiatry 1974;125:500-7.

34 Hannay DR. Mental health and high flats. $\mathcal{F}$ Chron Dis 1981 34:431-2.

35 Keithley J, Byrne D, Harrisson S, McCarthy P. Health and housing conditions in public sector housing estates. Public Health 1984;98:344-53.

36 Blackman T, Evason E, Melaugh M, Woods R. Housing and health: a case study of two areas of Belfast. fournal and health: a case study of two
of Social Policy 1989;18:1-26.

37 Birtchnell J, Masters N, Deahl M. Depression and the physical environment: a study of young married women physical environment: a study of young married women
on a London housing estate. Br $\mathcal{f}$ Psychiatr 1988;153: on a Lonc.

38 Hunt SM, Martin CJ, Platt SD. Housing and health in a deprived area of Edinburgh. In: Unhealthy housing: a diagnosis. Warwick: University of Warwick, 1986.

39 Hunt SM. Emotional distress and bad housing. Health and Hygiene 1990;11:72-9.

40 Semell E, Scholes W. Sound insulation performance between dwellings built in the early 1970s. Garston: Building Research Establishment, 1978

41 Gloag D. Noise and health: public and private responsibility. BMF 1980;281:1404-7.

42 Hyndman SJ. Housing dampness and health amongst British Bengalis in East London. Soc Sci Med 1990;30:131-41.

43 Packer CN, Stewart-Brown S, Fowle SE. Damp housing and adult health: results from a lifestyle study in Worcester, England. $f$ Epidemiol Community Health 1994;48:555-9.

44 Townsend P. Deprivation. Fournal of Social Policy 1987;16. 125-46.

45 Davey Smith G, Bartley M, Blane D. The Black report on socioeconomic inequalities in health 10 years on. $B M F$ 1990;301:373-7.

46 Bartley M, Popay J, Plewis I. Domestic conditions, paid employment and women's experience of ill-health. Societ Health and Illness 1992;14:313-43.

47 Carstairs V, Morris R. Deprivation and mortality: an alternative to social class? Community Medicine 1989;11: 210-19.

48 Ezzy D. Unemployment and mental health: a critical review. Soc Sci Med 1993;37:41-52.

49 Platt S, Kreitman N. Trends in parasuicide and un employment among men in Edinburgh, 1968-82. BMF 1984;289:1029-32.

50 Fryer D. The experience of unemployment in social context. In: Fisher S, Reason J, eds. Handbook of life stress, cognition and health. Chichester: John Wiley, 1988;211-38.

51 Markus TA. An investigation of condensation and dampness. Glasgow: University of Strathclyde, 1985.

52 Goldberg D, Williams P. A user's guide to the general health questionnaire. London: NFER-Nelson, 1991.

53 Fitzpatrick R, Hinton J, Newman S, Scambler G, Thompson J, eds. The experience of illness. London: Tavistock Publications, 1984

54 Lowry S. Housing and health. London: BMJ, 1988

55 Mitchell R. Some social implications of high density housing American Social Revue 1971;36:18-29.

56 Blane D. An assessment of the Black report's explanation of health inequalities. Sociology of Health and Illness 1985; $7: 423-45$. 